\title{
The Arabidopsis translocator protein (AtTSPO) is regulated at multiple levels in response to salt stress and perturbations in tetrapyrrole metabolism
}

Emilia Balsemão-Pires ${ }^{1,2}$, Yvon Jaillais ${ }^{2,3}$, Bradley JSC Olson², Leonardo R Andrade ${ }^{4}$, James G Umen², Joanne Chory ${ }^{2,3^{*}}$ and Gilberto Sachetto-Martins ${ }^{1 *}$

\begin{abstract}
Background: The translocator protein $18 \mathrm{kDa}$ (TSPO), previously known as the peripheral-type benzodiazepine receptor (PBR), is important for many cellular functions in mammals and bacteria, such as steroid biosynthesis, cellular respiration, cell proliferation, apoptosis, immunomodulation, transport of porphyrins and anions. Arabidopsis thaliana contains a single TSPO/PBR-related gene with a 40 amino acid N-terminal extension compared to its homologs in bacteria or mammals suggesting it might be chloroplast or mitochondrial localized.

Results: To test if the TSPO N-terminal extension targets it to organelles, we fused three potential translational start sites in the TSPO cDNA to the N-terminus of GFP (AtTSPO:eGFP). The location of the AtTSPO:eGFP fusion protein was found to depend on the translational start position and the conditions under which plants were grown. Full-length AtTSPO:eGFP fusion protein was found in the endoplasmic reticulum and in vesicles of unknown identity when plants were grown in standard conditions. However, full length AtTSPO:eGFP localized to chloroplasts when grown in the presence of $150 \mathrm{mM} \mathrm{NaCl}$, conditions of salt stress. In contrast, when AtTSPO:eGFP was truncated to the second or third start codon at amino acid position 21 or 42, the fusion protein co-localized with a mitochondrial marker in standard conditions. Using promoter GUS fusions, GRT-PCR, fluorescent protein tagging, and chloroplast fractionation approaches, we demonstrate that AtTSPO levels are regulated at the transcriptional, post-transcriptional and post-translational levels in response to abiotic stress conditions. Saltresponsive genes are increased in a tspo-1 knock-down mutant compared to wild type under conditions of salt stress, while they are decreased when AtTSPO is overexpressed. Mutations in tetrapyrrole biosynthesis genes and the application of chlorophyll or carotenoid biosynthesis inhibitors also affect AtTSPO expression.

Conclusion: Our data suggest that AtTSPO plays a role in the response of Arabidopsis to high salt stress. Salt stress leads to re-localization of the AtTSPO from the ER to chloroplasts through its N-terminal extension. In addition, our results show that AtTSPO is regulated at the transcriptional level in tetrapyrrole biosynthetic mutants. Thus, we propose that AtTSPO may play a role in transporting tetrapyrrole intermediates during salt stress and other conditions in which tetrapyrrole metabolism is compromised.
\end{abstract}

Keywords: plant TSPO, subcellular localization, abiotic stress, regulation, chloroplast

\footnotetext{
* Correspondence: chory@salk.edu; sachetto@biologia.ufrj.br

'Laboratório de Genômica Funcional e Transdução de Sinal, Departamento

de Genética, Universidade Federal do Rio de Janeiro, Rio de Janeiro, Brazil

${ }^{2}$ Plant Biology Laboratory, The Salk Institute, 10010 North Torrey Pines Road,

La Jolla, CA 92037, USA

Full list of author information is available at the end of the article
} 


\section{Background}

Higher plants synthesize four major tetrapyrroles (chlorophyll, haem, sirohaem and phytochromobilin) via a common branched pathway [1-3] (Additional file 1). In metazoans, heme and siroheme are synthesized in mitochondria, but in plants tetrapyrrole biosynthesis is plastid-localized, suggesting that tetrapyrroles are transported from the chloroplast to the mitochondria. This suggests that late stages of the heme biosynthetic pathway are present in both chloroplasts and mitochondria (Additional file 1). The concentration of tetrapyrrole intermediates is tightly controlled because these compounds are photoreactive and can generate reactive oxygen species (ROS). Additionally, many of the enzymes in this pathway are regulated by environmental stimuli and development signals $[4,5]$.

In mammals, an $18-\mathrm{kDa}$ peripheral-type benzodiazepine receptor (TSPO/PBR) is localized in the outer mitochondrial membrane [6] where it binds other proteins, such as the 34-kDa voltage-dependent anion channel and the inner membrane adenine nucleotide carrier [7]. TSPO was originally named the "peripheral benzodiazepine receptor" (PBR), however, it has more recently been renamed "TSPO" reflecting its structural and functional similarity to the bacterial tryptophan-rich sensory protein [8].

TSPO primarily functions to transport heme, porphyrins, steroids and anions [8-11]. However, TSPO proteins are also important for cellular respiration [12], cell proliferation [13] and apoptosis [14]. For example, in erythroids, in response to stress, TSPO is important for transporting porphyrins, which induce the expression of heme biosynthesis genes. Likewise, in mouse erythroleukemia cells TSPO has been shown to transport protoporphyrin IX playing a key role in tetrapyrrole and heme biosynthesis [15].

In the $\alpha$-proteobacterium Rhodobacter sphaeroides TSPO is localized in the outer membrane and its expression is induced by oxygen [16]. Under conditions of high oxygen, TSPO negatively regulates the expression of photosynthetic genes by exporting excess intermediates of the tetrapyrrole pathway, such as $\mathrm{Mg-}$ Protoporphyrin IX (Mg-ProtoIX) and MgProtoIX Monomethyl ester [17]. The rat TSPO homologue complements the Rhodobacter tspo mutant, suggesting that the function of TSPO is conserved in $R$. sphaeroides and metazoans [18].

Evidence for a functional TSPO protein in Arabidopsis thaliana and other plants has been previously reported [19]. Transport studies with the recombinant Arabidopsis TSPO in Escherichia coli revealed a benzodiazepinestimulated high-affinity uptake of protoporphyrin and cholesterol, leading to the hypothesis that the Arabidopsis homologue functions in the transport of protoporphyrinogen IX to the mitochondria where heme can be synthesized. However, the role of AtTSPO in plant metabolism is still unknown.

In animals and yeast, TSPO is found in the outer membrane of the mitochondria $[6,20]$. However the localization of TSPO in plants remains controversial. Lindenman et al. [19] used immunogold staining to show that TSPO is localized in the outer membrane of plastids and mitochondria in Digitalis lanata leaves. However, follow up Western blot experiments could only detect TSPO in mitochondrial fractions. In a separate study, TSPO was found in nuclear fractions prepared from Solanum tuberosum meristematic tissues, while low levels were detected in chloroplast fractions [21]. In Physcomitrella patens, transient expression of TSPO fused to the N-terminus of GFP, PpTSPO:GFP, localized to the mitochondria [22]. In Arabidopsis, fusion of TSPO to the C-terminus of YFP resulted in YFP:TSPO being found in the endoplasmic reticulum and the Golgi stacks [23].

The Arabidopsis genome contains a single TSPOrelated gene (AtTSPO). The predicted protein shares a high degree of similarity to the central domain of its bacterial and mammalian homologs. However, AtTSPO has a 40 amino acid $\mathrm{N}$-terminal extension that is not present in either bacteria or mammals. Moreover, within these 40 amino acids are three in-frame ATG-codons that could code for the first methionine (at positions M1, M21 and M42) (Additional file 2) [19]. To determine whether this region contains organellar targeting information, we developed a series of fusion proteins using the 3 different start sites. Our results demonstrate that AtTSPO was found in different organellar compartments depending on environmental stress. These results, along with analysis of an insertional mutation and expression studies, show that AtTSPO plays an important role in allowing Arabidopsis to cope with high salt stress.

\section{Results}

\section{Induction AtTSPO gene expression by abiotic stress}

In Physcomitrella patens, the expression of PpTSPO- 1 is induced by salt stress and abscisic acid (ABA) [22]. AtTSPO is also induced by salt stress in Arabidopsis [24], as well as in Arabidopsis cell cultures [23]. We further defined the transcript abundance of AtTSPO in 5-day old seedlings treated with $\mathrm{NaCl}$, mannitol, $\mathrm{ABA}$ and methyl viologen (MV), by extracting total RNA from these plants and performing quantitative real-time PCR (qRT-PCR).

Compared to untreated plants, $150 \mathrm{mM} \mathrm{NaCl}, 250$ mM mannitol, $1 \mu \mathrm{M}$ ABA and $0.2 \mu \mathrm{M}$ methyl viologen (MV) resulted in increased AtTSPO expression (Figure 1A). The kinetics of AtTSPO induction by $\mathrm{NaCl}$ and 
ABA stress were similar, peaking 3 hours after treatment and slowly decreasing between 6-25 h (Figure 1A-a and $1 \mathrm{~A}-\mathrm{b}$ respectively). Addition of mannitol resulted in peak AtTSPO expression between 3-6 $\mathrm{h}$ and then slowly decreased in abundance (Figure 1A-a, 1A-b and 1A-c).
However mannitol treatment showed a two-fold induction compared to treatment with $\mathrm{NaCl}$ for $3 \mathrm{~h}$ (Figure $1 \mathrm{~A}-\mathrm{a}$ and $1 \mathrm{~A}-\mathrm{c}$ ), which suggests that AtTSPO is induced by osmotic stress rather than salt stress. AtTSPO is rapidly induced by MV treatment, showing induction at

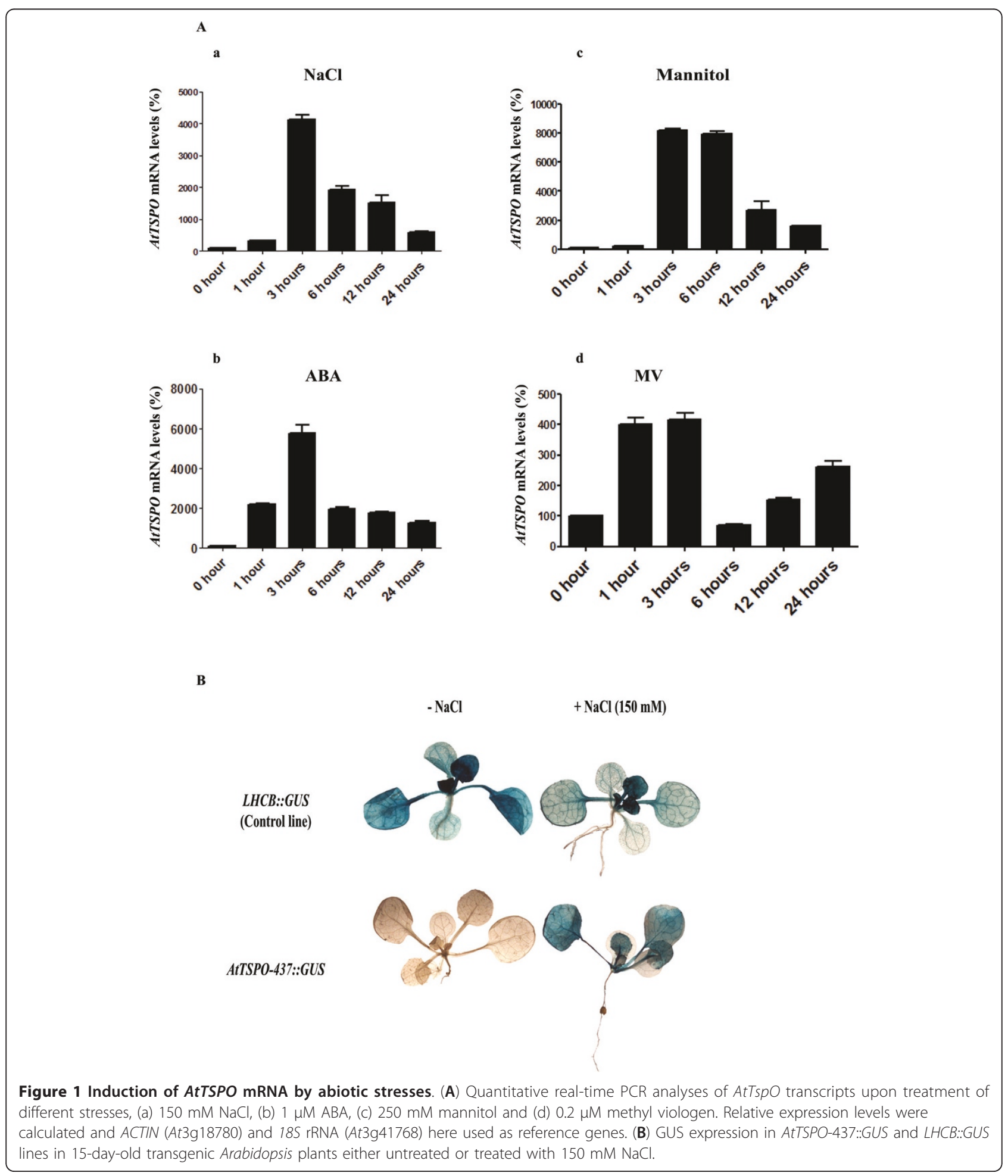


$1 \mathrm{~h}$, peaking by $3 \mathrm{~h}$ and then falling to basal levels within before increasing between 12-24 h (Figure 1A-d).

To determine if AtTSPO accumulation was a transcriptional response to $\mathrm{NaCl}$ stress, a construct, containing 437 bp upstream the putative translational start site of the AtT$S P O$ gene was fused to the uidA reporter gene (AtTSPO437::GUS), and transformed into plants, allowing in vivo analysis of AtTSPO transcriptional response to stress conditions. AtTSPO-437::GUS was found to be induced by 150 $\mathrm{mM} \mathrm{NaCl}$ within $3 \mathrm{~h}$ of treatment, which is similar to qRTPCR results of the endogenous gene (Figure $1 \mathrm{~B}$ ). In control experiments, $150 \mathrm{mM} \mathrm{NaCl}$ resulted in a small decrease of expression of LHCB::GUS (Figure 1B). Together these results suggest that the $437 \mathrm{bp}$ region of AtTSPO promoter is sufficient for transcriptional regulation of TSPO.

\section{Identification and characterization of AtTSPO mutants}

To determine the function of AtTSPO in vivo, we obtained a T-DNA insertional mutant (SALK_135023) [25] in AtTSPO. This line (tspo-1) was found to have two tandem T-DNA insertions, 123 bp upstream from the translational initiation codon of the AtTSPO gene (Figure 2A). Homozygous lines were then confirmed to be knock-down mutants by quantitative real time PCR (qRT-PCR) analysis. In this mutant, TSPO mRNA levels are about $20 \%$ of wild type (Figure $2 \mathrm{~B}$ ).

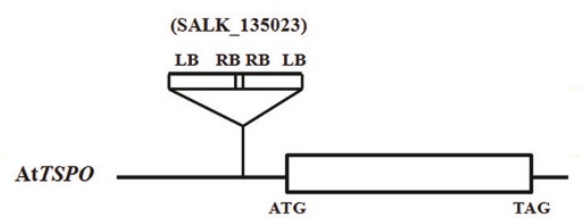

C

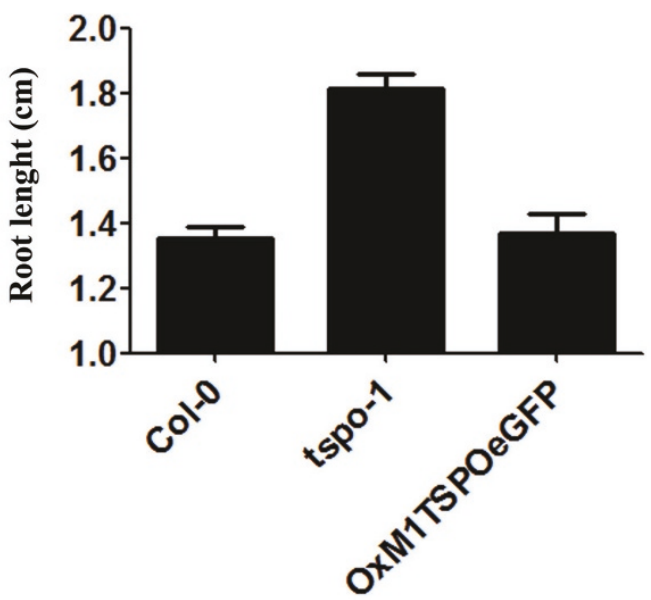

D
B
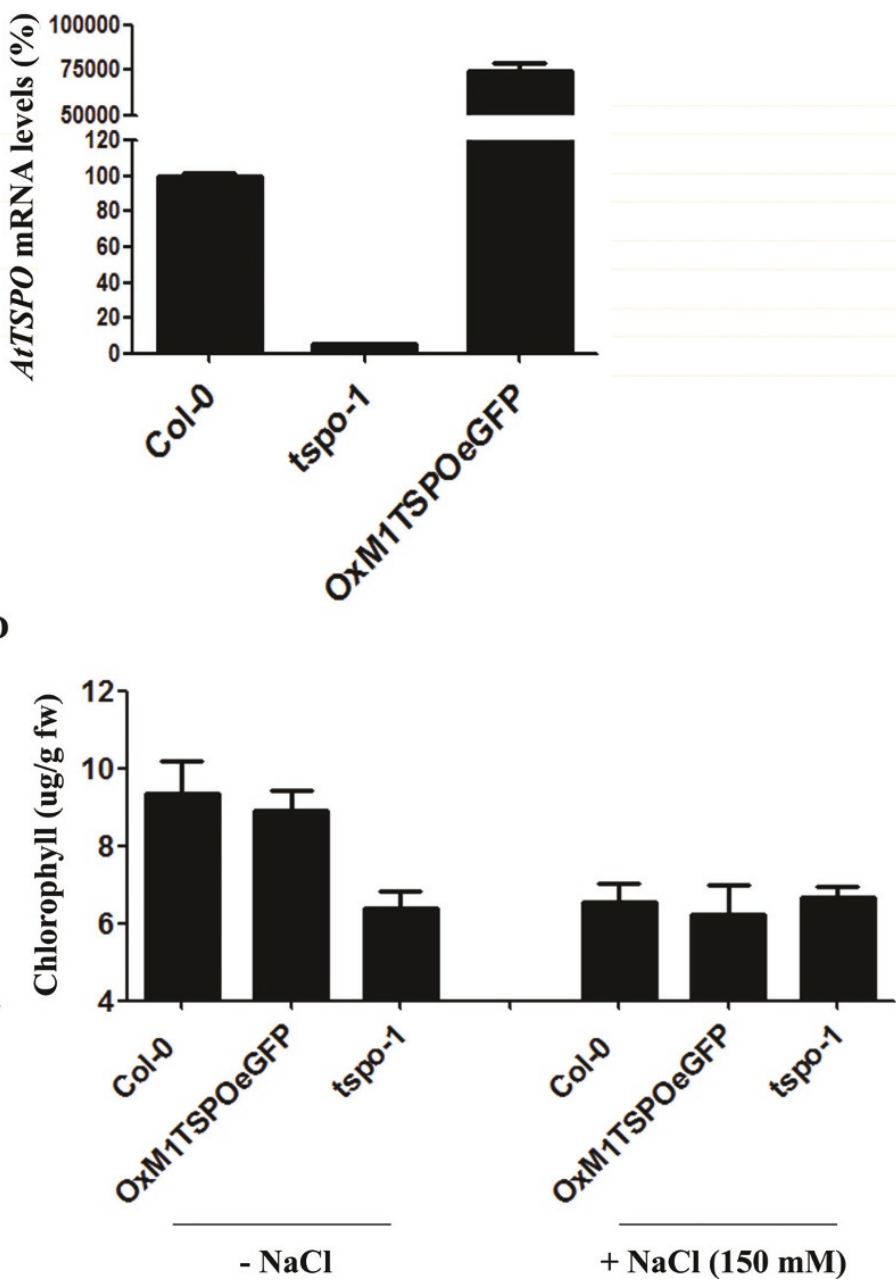

Figure 2 Phenotype of mutants with different levels of AtTSPO expression. (A) Schematic representation of isolated insertional mutant of AtTSPO in Arabidopsis. Two copies of the T-DNA were inserted in tandem $123 \mathrm{bp}$ upstream from the translational initiation codon of AtTSPO. (B) Total RNA was isolated from 5 day-old seedlings, reverse-transcribed and subjected to qRT-PCR. Data shown represent mean values obtained from independent amplification reactions $(n=3)$ and biological replicates $(n=2)$. Bars represent the standard error of biological replicates. (C) Root lengths of at least 100 individual 7-day-old seedlings grown in $16 \mathrm{~h}$ photoperiods. (D) Chlorophyll concentrations in 14-day-old, in vitrogrown plants of the indicated genotypes were determined spectrophotometrically. Values shown are means derived from three independent samples, each sample containing $100 \mathrm{mg}$ of fresh weight. Units are $\mu \mathrm{g}$ of chlorophyll $\mathrm{a}+\mathrm{b}$ per $\mathrm{g}$ of fresh weight (fw). 
AtTSPO fused or not to the N-terminus of GFP was constitutively overexpressed from the CaMV $35 \mathrm{~S}$ promoter in transgenic Arabidopsis lines (OxM1TSPO and OxM1TSPO:eGFP). We obtained 10 over-expression lines, but focused on the two homozygous lines that exhibited 500 fold over-expression of AtTSPO (Figure 2B). The tspo-1, OxM1TSPO:eGFP and wild-type lines were grown side-by-side on either Murashige \& Skoog (MS) agar medium or soil, and were monitored for possible abnormal phenotypes. The knock-down plants had longer roots compared to the wild type and the overexpression lines (Figure 2C). Moreover, tspo-1 accumulated $\sim 30 \%$ less chlorophyll than either the wild type or the overexpression lines in the presence of $150 \mathrm{mM}$ $\mathrm{NaCl}$ (Figure 2D).

\section{The expression of stress-response genes is enhanced in} tspo-1

AtTSPO expression was previously shown to be regulated by osmotic stress in germination and seedling growth assays [23]. Because TSPO regulates the expression of photosynthetic genes in $R$. sphaeroides [16], we hypothesized that tspo-1 or OxM1TSPO:eGFP mutants might have an impaired salt stress response. We examined the expression of some well-known salt stress-regulated genes (RAB18, ERD10 and DREB2A) [26]. As expected, stress marker genes were induced by $150 \mathrm{mM}$ $\mathrm{NaCl}$ in wild-type plants (Figure $3 \mathrm{~A}, \mathrm{~B}$ and $3 \mathrm{C}$ ). In $A t \mathrm{~T}$ SPO over-expression lines, the levels of DREB2A and RAB18 were lower but no significant change ERD10 expression was observed (Figure $3 \mathrm{~A}, \mathrm{~B}$ and $3 \mathrm{C}$ ).

In tspo- 1 mutants, $3 \mathrm{~h}$ of $150 \mathrm{mM} \mathrm{NaCl}$ treatment resulted in the increased expression of all three stress marker genes (Figure 3A, B and 3C). Taken together these results show that AtTSPO plays an important role in regulating the expression of stress response genes.

\section{Expression of light-regulated tetrapyrrole genes are repressed in the tspo-1 knock-down mutant}

Consistent with TSPO transporting tetrapyrroles $[17,19,27]$, tspo-1 plants accumulated less chlorophyll than wild-type plants (Figure 2D). Because we found that TSPO is involved in the salt stress response and because TSPO negatively regulates photosynthetic genes in $R$. sphaeroides [17]. We next analyzed the expression of a few key chlorophyll biosynthesis genes in tspo-1 plants.

Initially, we determined the mRNA levels of most of the key genes in the tetrapyrrole pathway (Additional file 1) in tspo-1 and gun5 mutants. GUN5 encodes the $\mathrm{H}$ subunit of chloroplastic $\mathrm{Mg}$-chelatase, which is involved in the perception of altered levels of tetrapyrrolic intermediates [28]. All tetrapyrrole biosynthetic genes known to be light-dependent [29] were found to be

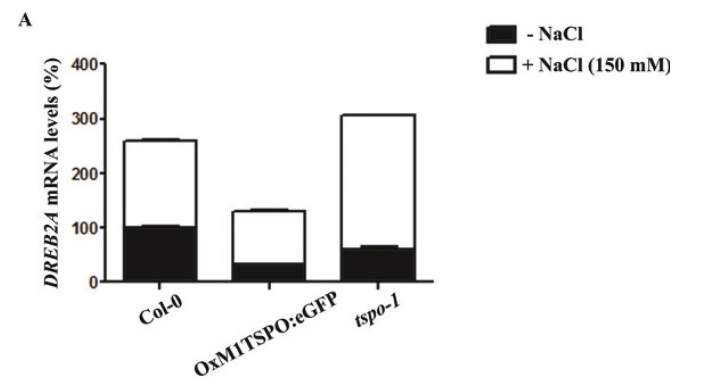

B

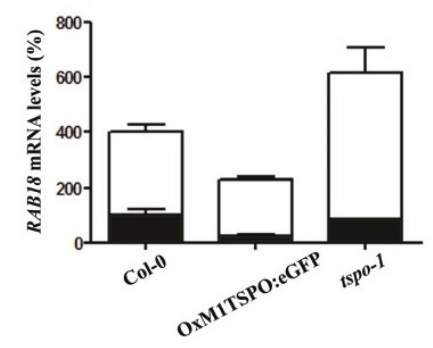

C

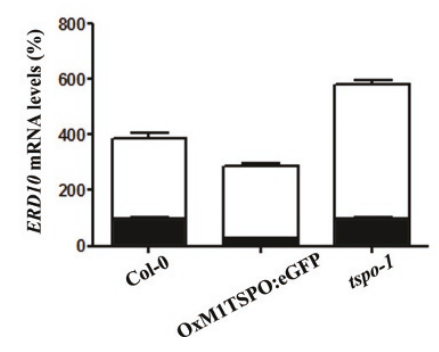

Figure 3 Stress-response genes are up-regulated in tspo-1 during salt stress. (A)-(C) Stress-induced gene expression in OxM1TSPO:eGFP and tspo-1 lines compared to wild type plants, by qPCR. 5-day-old seedlings grown under standard conditions and transferred for 3 hours to plates containing $150 \mathrm{mM} \mathrm{NaCl}$. (A) DREB2A, (B) RAB18 and (C) ERD10 mRNA levels were determined by quantitative GRT-PCR. Relative amounts were calculated and normalized relative to Col-0 non-treated (100\%). The ACTIN and 185 rRNA were used as reference genes. ACTIN, At3g18780; 18S RNA, At3g41768; RAB18, At5g66400; ERD10, At1g20450; DREB2A, At5g05410. Data shown represent mean values obtained from independent amplification reactions $(n=3)$ and biological replicates $(n=2)$. Relative expression levels were calculated. Bars represent the standard error of biological replicates.

down-regulated in tspo-1, as well as in gun 5 mutants [28] (Figure 4A, C, E, F, G and 4H), whereas the expression of the two light-independent genes were unaffected in wild-type and tspo-1 mutant (Figure 4B and 4D).

\section{Correlation of tetrapyrrole pathway flux and AtTSPO mRNA levels}

tspo-1 mutants present reduced levels of light-regulated tetrapyrrole metabolism genes (Figure 4A, C, E, F, G, 

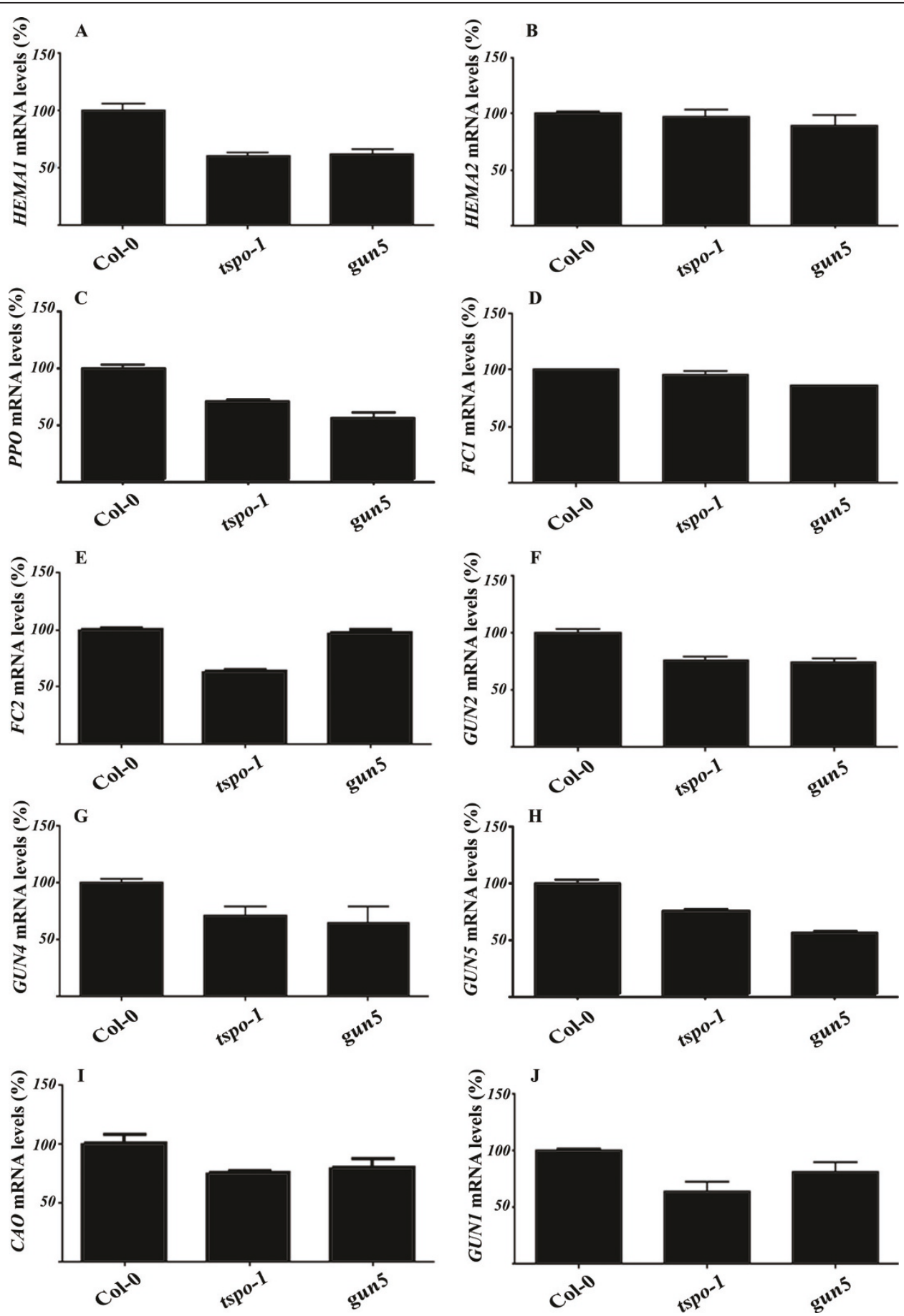

Figure 4 Expression of tetrapyrrole biosynthesis genes in tspo-1 mutant. qRT-PCR analyses of tetrapyrrole biosynthesis genes in Col-0, tspo1 and gun5 5-days-old seedlings grown in constant light. Relative amounts were calculated and normalized relative to Col-0 non-treated (100\%). With the exception of HEMA2 and $F C 1$, all the genes have been show to be regulated by light. The data are presented following the enzymes order in the tetrapyrrole biosynthesis. The ACTIN and 18S rRNA genes were used as control. ACTIN, At3g18780; 18S rRNA, At3g41768; (A) HEMA1 (Glutamyl-tRNA reductase 1 - At1g58290) (B) HEMA2 (Glutamyl-tRNA reductase 2 - At1g04490); (C) PPO (Protoporphyrinogen oxidase At4g01690); (D) FC1 (Ferrochelatase 1 - At5g26030); (E) FC2 (Ferrochelatase 2 - At2g30390); (F) GUN2 (Heme oxygenase 1 - At2g26670); (G) GUN4 (Regulator of Mg-porphyrin synthesis - At3g59400); (H) GUN5 (Mg-chelatase subunit H - At5g13630); (I) CAO (Chlorophyllide A oxygenase At1g44446); and (J) GUN1 (Pentatricopeptide repeat (PPR) protein - At2g31400). Data shown represent mean values obtained from independent amplification reactions $(n=3)$ and biological replicates $(n=2)$. Relative expression levels were calculated. Bars represent the standard error of biological replicates. 
and $4 \mathrm{H}$ ) and also have low chlorophyll content (Figure 2D). In order to investigate if decreasing flux of tetrapyrrole intermediates would affect AtTSPO expression in wild-type plants, we used two different drugs that interfere with tetrapyrrole biosynthesis, Gabaculine and Norflurazon. Gabaculine acts as a tetrapyrrole biosynthesis inhibitor by blocking the glutamate-1-semi aldehyde aminotransferase activity [30,31]. The herbicide
Norflurazon inhibits carotenoid biosynthesis and indirectly affects enzymes in tetrapyrrole biosynthesis [32-34]. AtTSPO mRNA levels increased 2-fold in plants treated with $50 \mu \mathrm{M}$ of gabaculine and up to 500 -fold after $500 \mathrm{nM}$ norflurazon treatment (Figure 5A).

To explore if AtTSPO expression is affected by genetic alterations of the tetrapyrrole biosynthesis pathway, we analyzed the expression of AtTSPO in different mutant

\section{A}

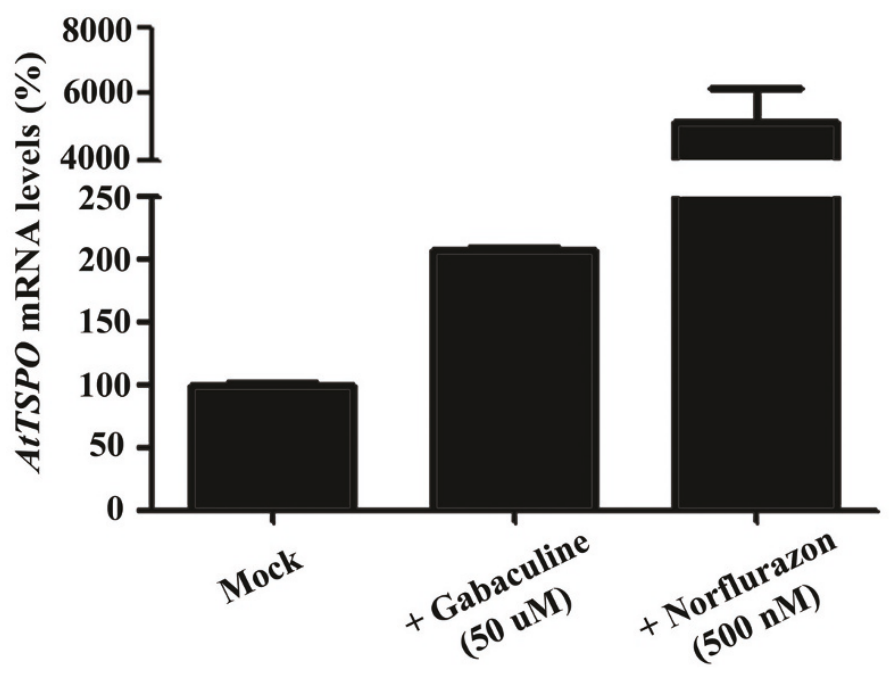

B

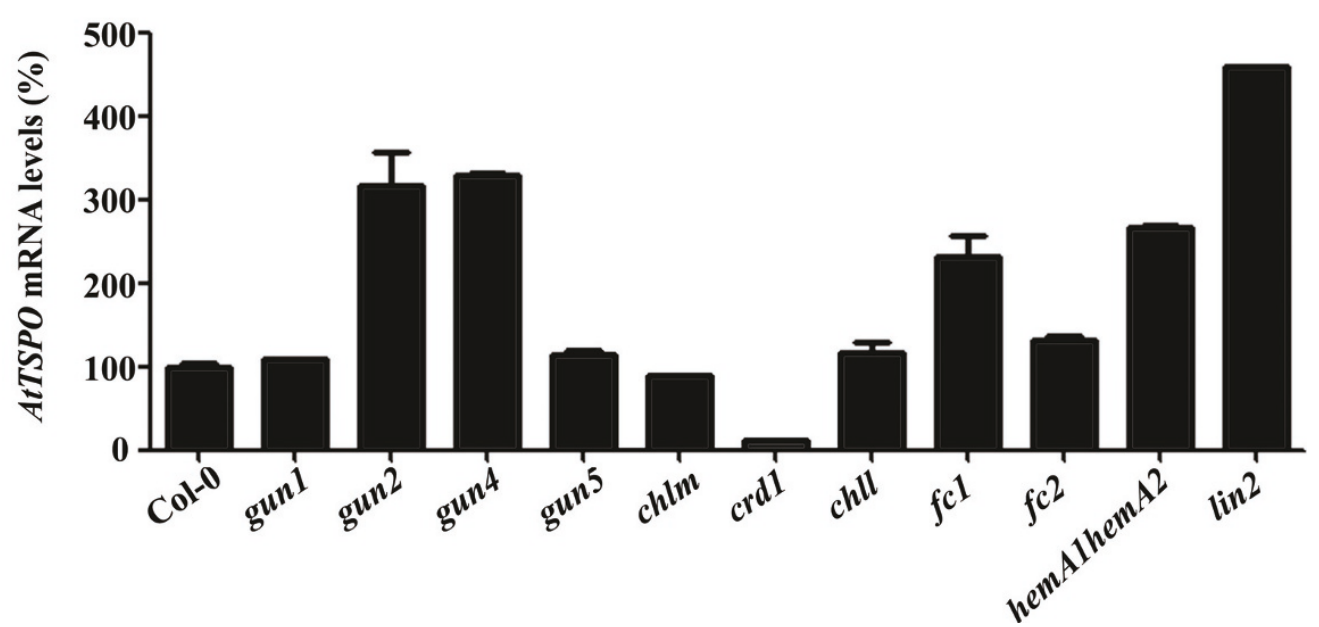

Figure 5 Relationship between tetrapyrrole flux and AtTSPO expression. (A) AtTSPO expression in wild-type plants germinated in $50 \mu \mathrm{M}$ of gabaculine or $500 \mathrm{nM}$ of norflurazon compared to untreated plants. (B) AtTSPO mRNA levels in different mutants of the tetrapyrrole pathway. Relative amounts were calculated and normalized relative to Col-0 non-treated (100\%). The ACTIN and 18S rRNA genes were used as control. ACTIN, At3g18780; 18S RNA, At3g41768. Data shown represent mean values obtained from independent amplification reactions $(n=3)$ and biological replicates $(n=2)$. Relative expression levels were calculated. Bars represent the standard error of biological replicates. 
backgrounds (Additional file 1). We found that AtTSPO levels are differently altered in various tetrapyrrole pathway mutants. AtTSPO steady-state levels were increased in gun2 (allele of hy1 - required for phytochromobilin synthesis from heme) [35], gun4 (mutant in the Protoporphyrin IX- and Mg-Protoporphyrin IX-binding protein) [36], $f c 1$ (mutant in the ferrochelatase) [37], hemA1hemA2 double mutant (mutant in both glutamyltRNA reductases genes) [38] and lin-2 (mutant in the coproporphyrinogen III oxidase) [39] (Figure 5B). The increased expression of AtTSPO in these mutants with reduced tetrapyrrole levels is consistent with $A t \mathrm{TSPO}$ transporting tetrapyrroles for roles in other compartments. The only biosynthetic mutant that resulted in reduced AtTSPO levels was crd1 (mutant in the Mgprotoporphyrin IX monomethyl ester cyclase) [40] (Figure 5B). All these mutations, in exception of $\operatorname{crd1}$ [41], inhibit somehow ALA synthesis, suggesting that disturbances in tetrapyrrole biosynthesis or accumulation affect AtTSPO mRNA expression.

\section{AtTSPO localization depends on the translational start site used}

AtTSPO (At2g47770) encodes a protein with a predicted molecular weight of $18 \mathrm{kDa}$. This protein has three possible in-frame ATG-start codons (M1, M21 and M42) in its N-terminal extension region (Additional file 2) [19].

Since reports of plant TSPO localization have resulted in different findings subcellular localization of plant TSPO $[19,21,23]$ we re-examined the subcellular location of $A t \mathrm{TSPO}$ and evaluated the roles of the N-terminal extension in targeting AtTSPO within the cell. Past studies $[20,23]$ have utilized N-terminal GFP fusions that might block potential organellar targeting of $A t \mathrm{~T}$ SPO, particularly mitochondrial or plastid localization. To allow proper targeting of $A t \mathrm{TSPO}$ fusions to GFP, AtTSPO was placed on the N-terminus of GFP. Three constructs were made, representing each of the potential start codons M1 (OxM1TSPO:eGFP), M21 (OxM21TSPO:eGFP) and M42 (OxM42TSPO:eGFP) and expressed from the CaMV $35 \mathrm{~S}$ promoter in Arabidopsis.

AtTSPO:eGFP subcellular localization was observed in root, hypocotyls and cotyledons of these lines by confocal microscopy. Full-length AtTSPO:eGFP (OxM1TSPO: eGFP) was found in the endoplasmic reticulum (ER) of the root tip (Figure 6A) and cotyledons (Figure 6C) in five day-old seedlings. However, in the hypocotyls of these plants, the fusion protein was found in the ER and in vesicles of unknown identity (Figure 6B). When M21 (OxM21TSPO:eGFP) or M42 (OxM42TSPO:eGFP) were used, the fusion proteins always co-localized with mitotracker, indicating a mitochondrial localization (Figure 6D, E, F, G, H and 6I) (Additional file 3). These results corroborate the previous observations of mitochondrial localization of TSPO in D. Lanata leaves by immunogold staining and in Arabidopsis by western blot experiments [19], as well as the endoplasmic reticulum located protein [23], indicating that the alternative use of three initiation codons could be important for AtTSPO localization and its post-translational control.

\section{OxM1TSPOeGFP becomes associated with plastids following high salt stress}

Having established a key role for AtTSPO in response to abiotic stress, we next examined the localization of $A t \mathrm{~T}$ SPO:eGFP fusion proteins in plants subjected to various stress conditions. 5 day-old seedlings were treated with $250 \mathrm{mM}$ mannitol, $1 \mu \mathrm{M}$ ABA, $0.2 \mu \mathrm{M}$ MV and 150 $\mathrm{mM} \mathrm{NaCl}$. After 18 hours of treatment, OxM1TSPO: eGFP became localized to the plastid (Figure 7G, H, I, J, $\mathrm{K}$ and $7 \mathrm{~L}$ ), while neither OxM21TSPO:eGFP nor OxM42TSPO:eGFP had altered localization even with 5 day extended $\mathrm{NaCl}$ treatment (data not shown). At TSPO:GFP localization did not change when plants were treated with mannitol, ABA or MV (data not shown).

To verify the expression levels of AtTSPO during salt stress, total protein from each lines was immunoblotted with antibodies to GFP (Figure 8A). In all cases, $A t \mathrm{~T}$ SPO:GFP protein was found to increase significantly after $24 \mathrm{~h}$ of salt treatment. Accumulation of AtTSPO: GFP was dependent on the presence of AtTSPO because empty vector controls using CaMV or Ubiquitin 10 [42] promoters to drive the expression of GFP did not change in response to salt stress (Figure $8 \mathrm{~A}$ and not shown). These results indicate that AtTSPO accumulation is regulated at the transcriptional, post-transcriptional and post-translational levels.

To confirm the location of AtTSPO we performed protease protection assays on isolated chloroplasts from OxM1TSPO:eGFP lines that were grown with or without $150 \mathrm{mM} \mathrm{NaCl}$ treatment. Following chloroplast isolation and protease protection, equal quantities of chloroplasts were subjected to immunoblotting with antibodies to GFP. AtTSPO was detected in chloroplast fractions near its predicted monomeric molecular mass (Additional file 4 and 5) in plants treated 18 hours with $150 \mathrm{mM} \mathrm{NaCl}$, but not in untreated plants (Figure 8B). Chloroplasts prepared from OxTSPO:eGFP lines occasionally displayed a lower molecular mass band that is approximately the mass of GFP. This band probably results from proteolysis between $A t \mathrm{TSPO}$ and the GFP tag during sample preparation, although we cannot rule out other possibilities since we do not have an antibody to AtTSPO protein itself. Antibodies to RuBisCo and D1 confirmed the integrity and presence of chloroplasts following protease protection. Antibodies to the cytosolic protein UGPase also verified these fractions were free of cytoplasmic contamination (Additional file 5). These 


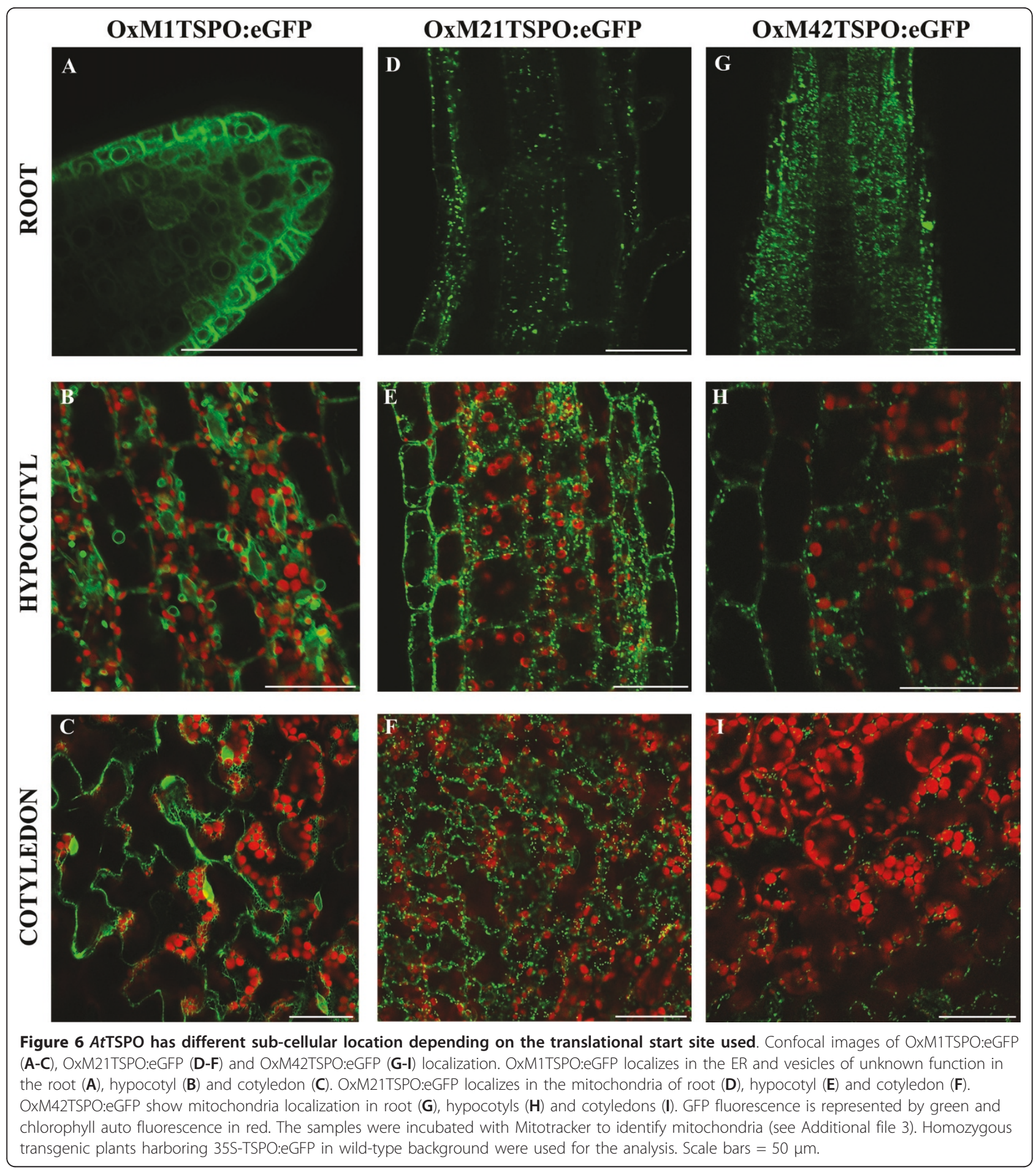

data together with confocal microscopy indicate that the region between the M1 and M21 is important for targeting AtTSPO to chloroplasts during salt stress. Since $A t$ TSPO was protected from trypsin digestion (Figure $8 \mathrm{~B})$, AtTSPO may be integral to the chloroplast outer envelope.

\section{Discussion}

The localization of TSPO in both chloroplasts and mitochondria is consistent with its role in porphyrin trafficking. Plant TSPO has been proposed to participate in the interaction between plastid and mitochondrial tetrapyrrole biosynthetic pathways [19]. In higher plants, 

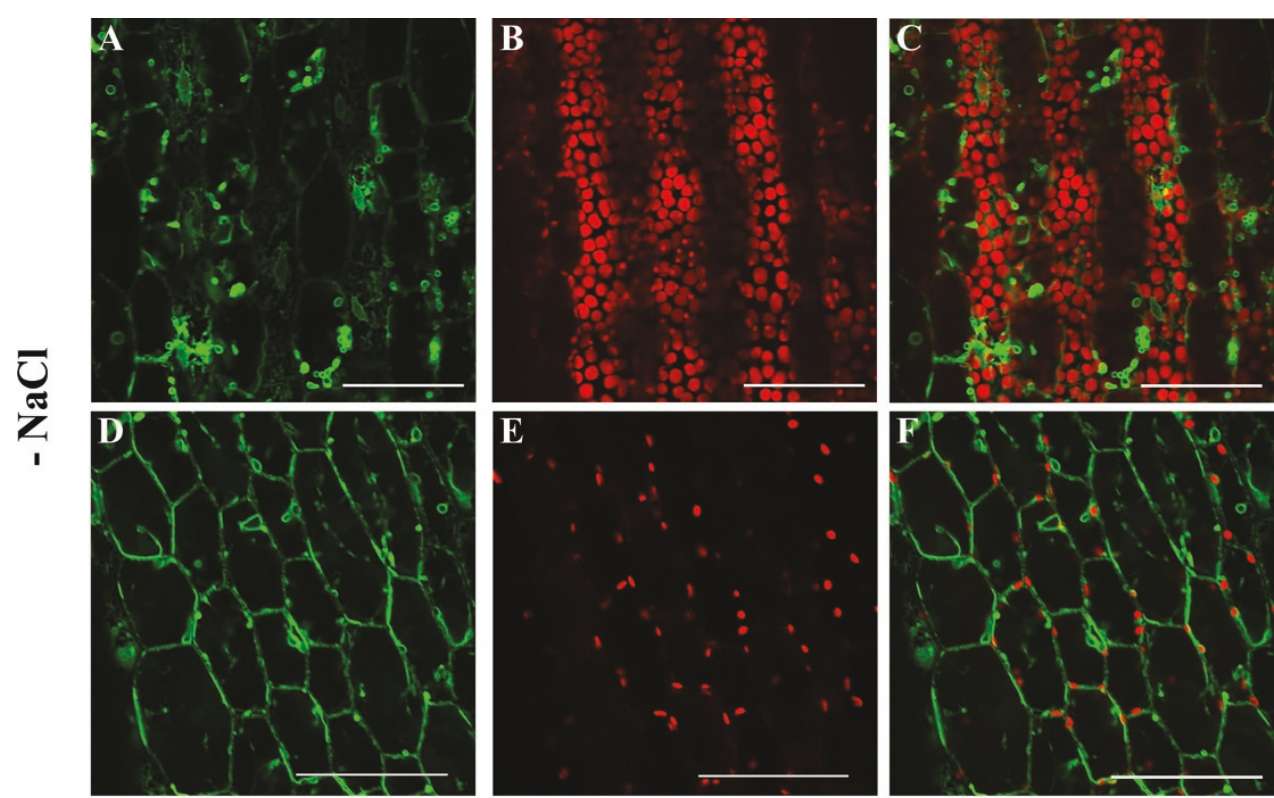

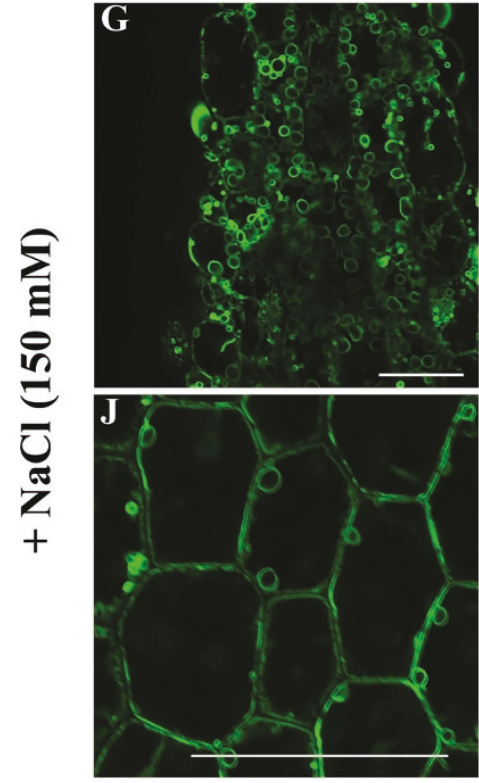

GFP
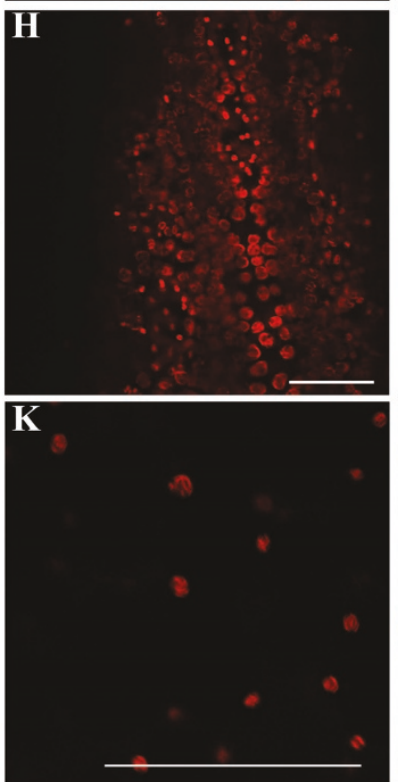

CHLOROPHYLL
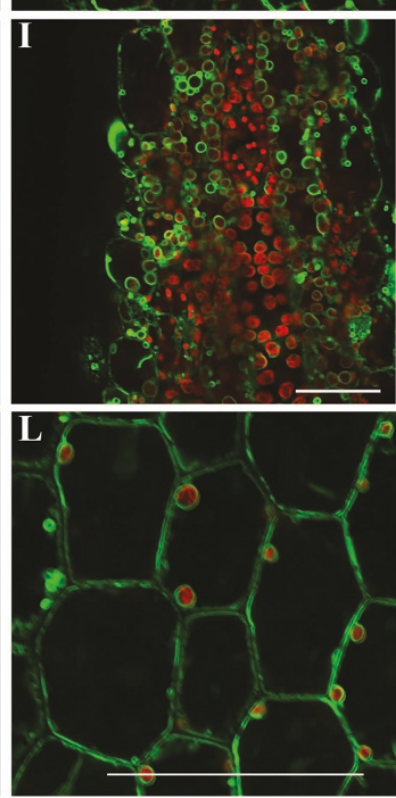

MERGE

Figure 7 OxM1TSPOeGFP localizes in chloroplasts upon salt stress. (A-F) Confocal analyses show OxM1TSPO:eGFP localization in the ER and vesicles of unknown function in hypocotyls of 5-day-old seedlings grown in the standard conditions. (G-L) Confocal analyses show OxM1TSPO: eGFP chloroplast localization in hypocotyls of 5-day-old seedlings grown in the presence of $150 \mathrm{mM} \mathrm{NaCl}$. GFP fluorescence channel is represented in green and chlorophyll auto fluorescence channel is represented in red. Homozygous transgenic plants harboring 35S-TSPO:eGFP in wild-type background were used for the analysis. Scale bars $=50 \mu \mathrm{m}$.

tetrapyrroles are synthesized almost exclusively in plastids, with the exception of the two last steps of heme synthesis that may occur in both chloroplasts and mitochondria. If AtTSPO is involved in tetrapyrrole transport [19], it is reasonable to assume that AtTSPO may translocate tetrapyrrole intermediates across organellar membranes, explaining why plants would need chloroplastic and mitochondrial isoforms of TSPO.
Consistent with this hypothesis, the $A t \mathrm{TSPO}$ protein is longer than its mammalian and bacterial counterparts. The targeting determinants for chloroplasts and mitochondria are usually located at the $\mathrm{N}$-terminus of the protein; therefore, a fusion protein with GFP fused to the C-terminus of TSPO was made. Using this strategy we demonstrated that AtTSPO had different sub-cellular localization patterns depending on the translational start 


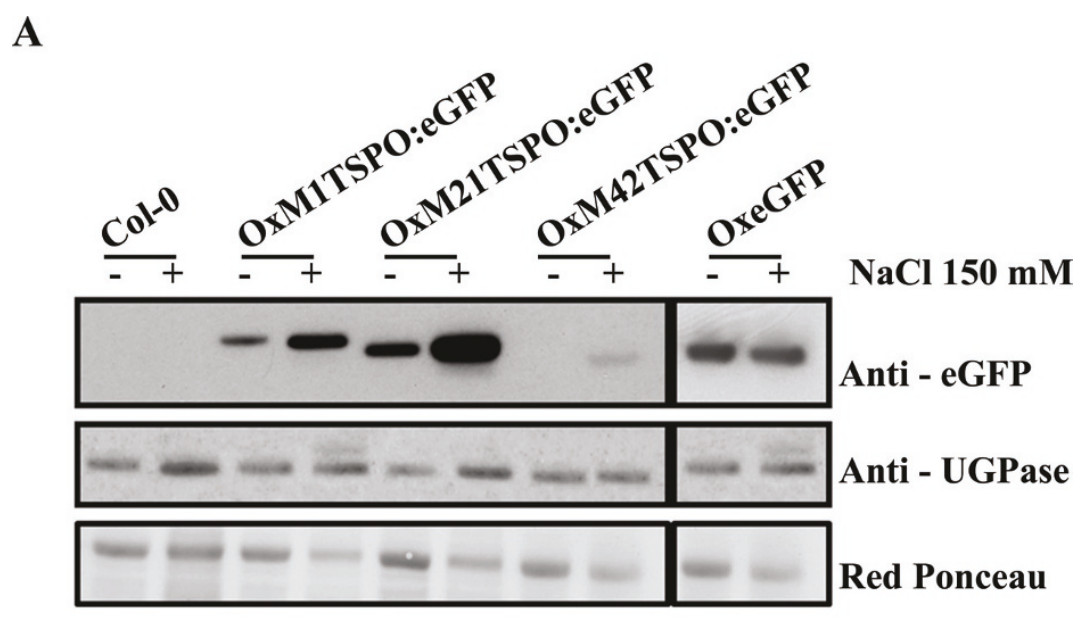

B

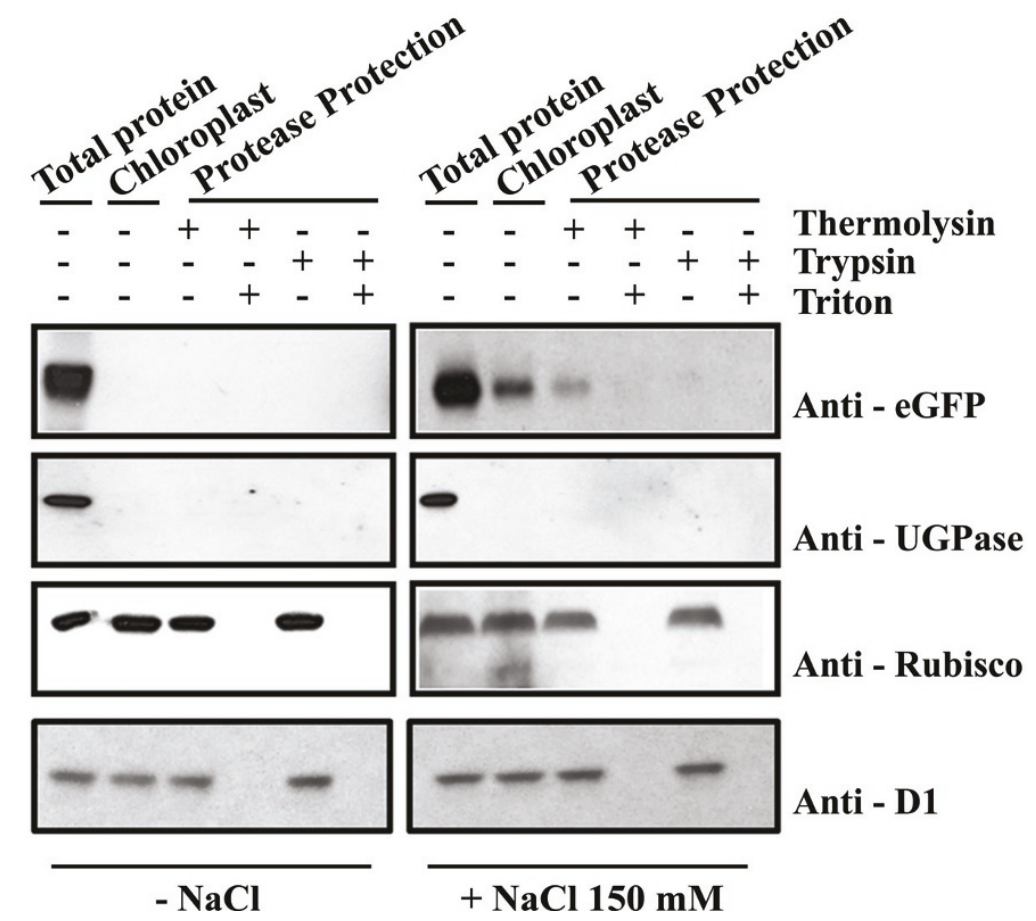

Figure 8 AtTSPO accumulation and chloroplast localization upon salt stress. (A) Immunoblot analysis of OxAtTSPO:eGFP (OxM1TSPO:eGFP, OxM21TSPO:eGFP and OxM42TSPO:eGFP) fusion proteins detected in plants with an antibody to GFP. Plants were untreated, or treated with 150 $\mathrm{mM} \mathrm{NaCl}$. As a control wild-type plants and plants over-expressing GFP (OxeGFP) seedlings were used. (B) Anti-GFP immunoblot of trypsinized chloroplasts from Arabidopsis plants either untreated or treated with $150 \mathrm{mM} \mathrm{NaCl}$. Control immunoblots were probed with antibodies chloroplast proteins RuBisCo and D1; and to cytosolic UGPase. Each lane represents equal amounts of chloroplasts.

codon, tissue type or the abiotic stress to which the plant was subjected. Placement of the GFP fusion on either the $\mathrm{N}$ - or C-terminus of TSPO probably explains the inconsistencies in previous studies $[19,21,23]$ compared to those presented here. The construct used by Guillaumot [23] had the YFP fused to the N-terminus of
AtTSPO, which could potentially mask the transit peptide that targets TSPO to chloroplasts and mitochondria. Indeed, a similar case was observed recently for the Arabidopsis HEMERA protein (HMR). When HMR had CFP on its C-terminus, it was localized exclusively in chloroplasts, however, fusion of HMR to the C-terminus 
of YFP (YFP-HMR) was localized to the nucleus and cytoplasm but not chloroplasts [43].

Salt-stress of Arabidopsis results in movement of ERlocalized AtM1TSPO:eGFP to the chloroplast. We also demonstrated that the different start codons within the TSPO N-terminal extension could target the TSPO protein to different organelles. Other plant proteins such as MDAR (Arabidopsis Monodehydroascorbate Reductase) and tRNA nucleotidyltransferase $[44,45]$ are also known to be targeted to different organelles owing to alternative transcriptionsal start sites. Thus, it is tempting to speculate that, cloroplastic AtTSPO may protect the chloroplast from salt stress damage and the mitochondrial AtTSPO may normally import chloroplast-synthesized porphyrins into the mitochondria. Alterations in the sub-cellular localization of TSPO have been observed in mammals. The mammalian TSPO localizes to the mitochondrial outer membrane but during fast cell proliferation, such as metastatic processes, it relocates to the nuclear membrane, suggesting developmental control of its sub-cellular localization [46].

Our results suggest the existence of a chloroplast targeting region in $A t \mathrm{TSPO}$ that operates during salt stress. Constructs lacking the $\mathrm{N}$-terminus of $A t \mathrm{TSPO}$ (AtM2TSPO:eGFP and AtM3TSPO:eGFP) are not able to be target to this organelle. These results suggest that the first twenty aminoacids of AtTSPO may be part of the chloroplast targeting peptide of this protein. Further experiments should be conducted to precisely characterize this chloroplast targeting determinant.

TSPO localization in plant cells is complex, involving a relocation of the protein from ER and vesicles to chloroplasts during salt-stress. In recent years, several new mechanisms for import of proteins into chloroplasts have been proposed. For example, it is hypothesized that close contacts between the envelopes of chloroplasts, mitochondria and other organelle membranes could allow protein movement between them [47]. Such fusions have been observed between the mitochondria and ER [48], where it was suggested that vesicle associated membrane protein 1 (VAMP-1) might be involved in the docking of mitochondria to target membranes [49]. This, in turn, could facilitate a re-localization of proteins from mitochondria to other compartments. The recent discoveries of close intracellular membrane contacts in plants, namely between chloroplasts and the ER [50], as well as between mitochondria and the nucleus [51], corroborates this hypothesis. At the present moment it is not clear which pathway is used during AtTSPO relocation during salt-stress. However our data indicate that AtTSPO changes its localization during stress, and that it is also possible that the mitochondrial isoform observed previously by Frank $e t$ al. [22] in P. patens and by Lindenman et al. [19] in $D$. lanata and Arabidopsis could be generated in Arabidopsis by the use of alternative translation start codons.

Transcriptional levels of AtTSPO in wild-type Arabidopsis plants increase in response to salt, mannitol, $\mathrm{ABA}$ and paraquat. The promoter region of AtTSPO was also found to be sufficient for salt stress transcriptional response. The induction of AtTSPO by salt stress was also observed when constitutive promoters $(35 \mathrm{~S}$ and UBI10) were used to express AtTSPO, suggesting that the induction of $A t \mathrm{TSPO}$ occurs at both transcriptional and post-transcriptional levels.

AtTSPO over-expression lines have decreased levels of stress response genes (ERD10, DREB2A and RAB18), while tspo-1 mutants over express these genes. This suggests that AtTSPO expression and/or function is necessary for the proper regulation of these genes during stress conditions. These results also imply that AtTSPO is important for stress adaptation in Arabidopsis, and this idea is consistent with results from $P$. patens [22]. Since Rhodobacter TSPO is a negative regulator of photosynthetic genes [17], it is possible that AtTSPO operates similarly in regulating stress responsive genes in plants.

The precise function of AtTSPO in tetrapyrrole transport during salt stress remains to be established. There are, however, many reports suggesting that alterations in tetrapyrrole flow can be involved in salt tolerance. Exogenous 5-Aminolevulinate (ALA) can improve salt tolerance in higher plants [51-56]. It has been also shown that transgenic Arabidopsis, tobacco and rice that overproduce ALA have improved salt tolerance $[57,58]$. Abdelkader et al. [59] assumed that high salt stress inhibited chlorophyll accumulation mainly by reducing the rate of porphyrin formation, and Zhang et al. [58] showed that salt stress caused a significant decrease in heme content. Thus in higher plants, ALA and tetrapyrrole synthesis is sensitive to salt stress.

Additionally, we demonstrated that AtTSPO is important for tetrapyrrole flux and/or metabolism. The herbicide Norflurazon, a non-competitive inhibitor of phytoene desaturase, [31-33] and the neurotoxin Gabaculine, which inhibits tetrapyrrole biosynthesis by blocking glutamate-1-semi aldehyde aminotransferase activity $[29,30]$ were used in this study to decrease the flux through the tetrapyrrole biosynthesis pathways. Our data showed that mutations in tetrapyrrole biosynthesis genes and the application of these two different drugs that decrease flux of tetrapyrrole intermediates affect AtTSPO expression. All mutations tested that inhibit the synthesis of ALA increase AtTSPO mRNA steady-state levels. The same was observed when the formation of ALA is inhibited by the norflurazon and the gabaculine. The only mutant tested with decreased AtTSPO expression is $c r d 1$, which accumulates Mg-Protoporphyrin 
monomethyl ester and this accumulation does not affect the inhibition of ALA synthesis [40]. Finally, it is possible that AtTSPO could be involved in the partitioning of different tetrapyrrolic signal molecules within plant cells. The steady state levels of several light-regulated mRNAs of tetrapyrrole metabolism genes are downregulated in the tspo-1 mutant, suggesting that, AtTSPO could act as a regulator of tetrapyrrole biosynthesis similar to its bacterial counterpart [16].

\section{Conclusions}

TSPO has been shown to transport a number of small molecules in multiple organisms, however its function in plants is not known. Here we demonstrate that Arabidopsis TSPO is regulated at the transcriptional, post-transcriptional and post-translational levels in response to abiotic stress conditions such as salt stress. Our results suggest that AtTSPO can localize to ER and mitochondria, but when plants are salt stressed AtTSPO is found in chloroplasts. Also our data suggest that under normal conditions AtTSPO may be important for the import of chloroplastic synthesized heme into the mitochondria. However, targeting AtTSPO to the chloroplast during salt stress may protect chloroplasts from damage. In addition, tetrapyrrole intermediates has been suggested to operate in the chloroplast-to-nucleus retrograde signaling $[35,60]$. It is possible that AtTSPO could be involved in the partitioning of different tetrapyrrole signal molecules within plant cells depending on environmental conditions. AtTSPO may play a role in re-directing tetrapyrrole intermediates during salt stress or under conditions where tetrapyrrole metabolism is compromised. This is suggested by our finding that mutation or inhibition of the tetrapyrrole biosynthesis pathway increases AtTSPO expression. At the same time, $A t \mathrm{TSPO}$ may directly contribute to the detoxification of highly reactive porphyrins in the cytoplasm. We are currently investigating these possibilities.

\section{Methods}

\section{Plant material and growth conditions}

Arabidopsis thaliana seeds ecotype Col-0 were surface sterilized and plated on $\mathrm{MS}_{1 / 2}$ medium [61] with or without $50 \mathrm{mM}$ kanamycin. Seedlings were maintained for three days at $4^{\circ} \mathrm{C}$ and than grown under $16 / 8$ hours light/dark cycles at $23^{\circ} \mathrm{C}$ in growth chambers. Root length measurements were conducted using plants grown on vertically oriented in standard conditions for 10 days. For abiotic stress treatment, $150 \mathrm{mM} \mathrm{NaCl}, 250$ mM mannitol, $1 \mu \mathrm{M}$ ABA (Sigma; St Louis, MO) or 0.2 $\mu \mathrm{M}$ paraquat was added to $\mathrm{MS}_{1 / 2}$ agar plates, and the 5day-old seedlings were incubated under normal growth condition. For Norflurazon or Gabaculine experiments seeds were plated on $\mathrm{MS}_{1 / 2}$ containing 1 or $2 \%$ sucrose with or without $5 \mu \mathrm{M}$ norflurazon (Sandoz
Pharmaceuticals; Vienna, Austria) or $50 \mu \mathrm{M}$ of gabaculine (Sigma, USA). All experiments were repeated three times independently and the average was calculated.

\section{RNA extraction and qRT-PCR analysis}

Total RNA was isolated using Spectrum ${ }^{\mathrm{TM}}$ Plant Total RNA Kit (Sigma \#STRN250-1KT), according to manufacturer's instructions. One microgram of total RNA was added to each cDNA synthesis reaction using the First Strand cDNA Synthesis Kit (\#K1611). For qRTPCR, DNA amplification was performed in the presence of SYBR ${ }^{\circledR}$ Green qPCR Detection (Invitrogen) in a MyIQ ${ }^{\mathrm{TM}}$ Single Color Real-Time PCR Detection System (BioRad), using the primer pairs at table 1. The cycle

Table 1 Primers used for quantitative real time PCR (qRTPCR)

\begin{tabular}{|c|c|}
\hline PRIMER NAME FOR qPCR & SEQUENCE \\
\hline TSPO FWD & ACAAAGGAAAACGCGATCAAA \\
\hline TSPO RVS & ACTTGAGACCACGTTTCGCC \\
\hline GUN1 FWD & GCGATTCTGAATGCTTGCAG \\
\hline GUN1 RVS & AGGAGCCATACATTCTCTCT \\
\hline GUN2 FWD & AGACTCCAATTTCCCAACTT \\
\hline GUN2 RVS & TTACCAGGACGTGTTGGTTC \\
\hline GUN4 FWD & GAAACCGCGACCATATTCGAC \\
\hline GUN4 RVS & CGGCTTCTCCGGATATCTGAA \\
\hline GUN5 FWD & CATCCACTTGCTCCAACCATG \\
\hline GUN5 RVS & CCGACAACCGTTGCATCTIT \\
\hline HEMA1 FWD & GCTTCCGCAGTCTTCAAACG \\
\hline HEMA1 RVS & CCAGCGCCAATTACACACATC \\
\hline HEMA2 FWD & AGCTCCTGCACGGTCCAAT \\
\hline HEMA2 RVS & TGCTATCGTTCCCATCGCAT \\
\hline FC1 FWD & ATACCAGAGTCGTGTTGGCCC \\
\hline FC1 RVS & TCATCGGTGTATGGCTTCAGC \\
\hline FC2 FWD & TGGTGCTATGGCTGTCTCAAAC \\
\hline FC2 RVS & AGCGGAACTAACGACTGTCGA \\
\hline CAO FWD & TGATGAGCCACCTGCACCTAT \\
\hline CAO RVS & AAGTAAACCGTGTTCCACCGG \\
\hline PPO FWD & GCTTCTTCCGTCGTTITCGAA \\
\hline PPO RVS & TTGAAGATCCGACGGTTGGTC \\
\hline DREB2A FWD & CAGGCTTAAATCAGGACCGG \\
\hline DREB2A RVS & ATGAACCGTTGGCAACACTG \\
\hline ERD10 FWD & CACCGTTCCAGAGCAGGAGA \\
\hline ERD10 RVS & GCCGATGATTCCTCTGTTGC \\
\hline RAB18 FWD & AAGGAGAAGTTGCCAGGTCATC \\
\hline RAB18 RVS & CATCGCTTGAGCTTGACCAG \\
\hline ACTIN 2/8 FWD & TCTTGTTCCAGCCCTCGTIT \\
\hline ACTIN 2/8 RVS & TCTCGTGGATTCCAGCAGCT \\
\hline 18S RNA FWD & TATAGGACTCCGCTGGCACC \\
\hline $18 S$ RNA RVS & CCCGGAACCCAAAAACTTTG \\
\hline
\end{tabular}


use was: $95 \mathrm{C}, 1 \mathrm{~min}$ and $30 \mathrm{sec} ; 40 \times(95 \mathrm{C}, 10 \mathrm{sec} ; 60$ C, $1 \mathrm{~min})$; $95 \mathrm{C}, 1 \mathrm{~min} ; 60 \mathrm{C}, 1 \mathrm{~min}$ and $81 \times(60 \mathrm{C}, 10$ $\mathrm{sec})$. The relative mRNA levels were determined by normalizing the PCR threshold cycle number with Actin and $18 S R N A$. All experiments were repeated three times independently and the average was calculated.

\section{Verification of TSPO knock-out}

The tspo-1 T-DNA mutant, SALK_135023, was obtained from the Salk collection [24]. Homozygous mutants were isolated by PCR-based genotyping using gene specific PCR primers AtTSPO-LP and AtTSPO-BP together with LBa1 (Table 2). Only homozygous lines were used for the phenotypic investigation.

\section{Construction of AtTSPO GUS Fusion Vector and GUS Assay}

The 437 bp upstream of the translational star site of the AtTSPO gene (At2g47770) was translational fused into uid $A$ gene in pKGWFS7 vector by Gateway ${ }^{\circledR}$ (Invitrogen $^{\mathrm{TM}}$ ) [62] and introduced into Arabidopsis via Agrobacterium-mediated transformation [63]. For cloning primers and constructs information see Tables 2 and 3, respectively. For histochemical GUS expression plant samples were soaked at $37^{\circ} \mathrm{C}$ for 16 hours in GUS assay solution (1 mm 5-bromo-4-chloro-3-indolylglucronide, $0.5 \mathrm{~mm} \mathrm{~K}_{3} \mathrm{Fe}(\mathrm{CN})_{6}, 0.5 \mathrm{~mm} \mathrm{~K}_{4} \mathrm{Fe}(\mathrm{CN})_{6}, 0.3 \%$ (v/v) Triton $\mathrm{X}-100,20 \%(\mathrm{v} / \mathrm{v})$ methanol, and $50 \mathrm{~mm}$ inorganic phosphate-buffered saline). The reaction was further conducted at $37^{\circ} \mathrm{C}$ in the dark for a maximum of 16 hours.

\section{Subcellular localization of AtTSPO fusion proteins}

For the GFP fusion constructs, clones containing the coding region of AtTSPO as well as fusions starting at methionine 21 and 42 were generated and cloned into pK7FWG2 [62] (Table 3) according to the manufacturer's instructions (Invitrogen, CA, USA). Primers used were: AtTSPO M1: TSPO NT1 and TSPO CT1; AtTSPO M2: TSPO NT2 and TSPO CT1; AtTSPO M3: TSPO NT3 and TSPO CT1; AtTSPO 80aa: TSPO NT1
Table 3 Constructs information

\begin{tabular}{lll}
\hline CONSTRUCT NAME & BINARY VECTOR & RESISTANCE IN PLANT \\
\hline UBQ10mCITRINE & pB7m34GW & basta \\
\hline UBQ10M1TSPOmCITRINE & pB7m34GW & basta \\
\hline UBQ10M2TSPOmCITRINE & pB7m34GW & basta \\
\hline UBQ10M3TSPOmCITRINE & pB7m34GW & basta \\
\hline OxeGFP & pK7FWG2 & kanamycin \\
\hline OxMITSPO:eGFP & pK7FWG2 & kanamycin \\
\hline OxM2TSPO:eGFP & pK7FWG2 & kanamycin \\
\hline OXM3TSPO:eGFP & pK7FWG2 & kanamycin \\
\hline AtTSPO-437::GUS & pKGWFS7 & kanamycin \\
\hline
\end{tabular}

and TSPO CT80 (Table 2). Arabidopsis thaliana was observed in a confocal laser scanning microscope Leica DM IRE2 (Leica microsystems). For the mitochondrialspecific staining, Arabidopsis seedlings were incubated in MitoTracker ${ }^{\circledR}$ Red CMXRos (Invitrogen, \#M7512) according to manufactures instructions. Excitation and emission wavelengths were 488 and 505-530 $\mathrm{nm}$ (BP 505-530 filter) for GFP and, 543 and 560-615 nm (BP 560-615 filter) for MitoTracker ${ }^{\circledR}$ respectively. All images were processed on Leica DM IRE2 Image Browser program (Leica microsystems).

\section{Determination of chlorophyll contents}

Seedlings at 10 days after germination were weighted, frozen in liquid nitrogen, and ground in $80 \%(\mathrm{v} / \mathrm{v})$ acetone. Ground tissue was centrifuged at 2,000 g for $5 \mathrm{~min}$ to pellet any insoluble material. The absorbance of the extracted chlorophyll at 645 and $663 \mathrm{~nm}$ was then determined. Chlorophyll ( $\mathrm{a}$ and $\mathrm{b}$ ) contents of the samples were determined according to Lichtenthaler [64].

\section{Chloroplast Isolation}

Isolation of chloroplasts from plate-grown Arabidopsis seedlings was performed as described previously [65]. Final resuspension of chloroplast was in buffer $(330 \mathrm{mM}$ sorbitol, $50 \mathrm{mM}$ HEPES-KOH, pH 8.0) at a concentration of $1 \mathrm{mg}$ chlorophyll $\mathrm{ml}^{-1}$.

Table 2 Primers used for cloning and genotyping

\begin{tabular}{cc}
\hline PRIMER NAME FOR GENOTYPING AND CLONING & SEQUENCE \\
\hline AtTSPO LP & agagcaaatcgcatcagcgtc \\
\hline AtTSPO RP & ggaacgtaaccggatcccaaa \\
\hline LBa1 & tggttcacgtagtgggccatcg \\
\hline TSPO NT1 & aaaaagcaggctccatggattctcaggaca \\
\hline TSPO NT2 & aaaaagcaggctccatggccgagacagagagg \\
\hline TSPO NT3 & aaaaagcaggctccatggcgaaacgtggtctc \\
\hline TSPO CT1 & agaaagctgggtccgcgacagcaagctttaca \\
\hline TSPO CT80 & agaaagctgggtcggacttagctcgattcccgta
\end{tabular}




\section{Immunoblotting}

Total protein was extracted from 10-day-old seedlings by adding protein extraction buffer $(50 \mathrm{mM}$ HEPES $\mathrm{pH}$ 7.9, $300 \mathrm{mM}$ Sucrose, $150 \mathrm{mM} \mathrm{NaCl}, 10 \mathrm{mM}$ Potassium acetate, protease inhibitors cocktail - Roche, 1\% (w/v) Triton, $1 \mathrm{mM}$ DTT). Ground tissue was centrifuged at $5,000 \times \mathrm{g}$ for $5 \mathrm{~min}$ to pellet the tissue and proteins were quantify by Bradford assay [66]. Samples were boiled for $5 \mathrm{~min}$ in $250 \mathrm{mM}$ Tris- $\mathrm{HCl}, \mathrm{pH} 6.8,10 \%(\mathrm{w} /$ v) SDS, $30 \%(\mathrm{v} / \mathrm{v})$ glycerol, $5 \%(\mathrm{v} / \mathrm{v}) \beta$ - mercaptoethanol and $0.02 \%(\mathrm{w} / \mathrm{v})$ bromophenol blue. SDS-PAGE was performed using standard procedures. Chloroplast protein samples were normalized loaded by equal amounts of total chlorophyll. Following SDS-PAGE, the separated proteins were transferred to a polyvinylidene difluoride membrane (Bio-Rad). For immunodetection, membranes were incubated with antibody against GFP (ROCHE, \#11814460001), UGPase (AGRISERA, \#AS05086), RuBisCo (AGRISERA, \#AS03037) and D1(AGRISERA, \#AS05084). With the exception of GFP detection that uses mouse secondary antibody, all the immunoreactive proteins were detected by using rabbit secondary antibody. The immunoreaction was detected by chemiluminescence kit (Thermo Scientific, \#34076) according to manufacturer's instructions.

\section{Additional material}

\section{Additional file 1: Schematic representation of tetrapyrrole} biosyntheses pathway in plants showing genes analyzed in this study. In blue, are the genes already described for each step in the pathway. The enzymes that correspond to these genes names and the AGI code are: HEMA1 (Glutamyl-tRNA reductase 1, At1g58290); HEMA2 (Glutamyl-tRNA reductase 2, At1g09940); HEMA3(Glutamyl-tRNA reductase 3, At2g31250); FLU (Regulator of ALA synthesis, At3g14110); LIN2 (Coproporphyrinogen oxidase 1, At1g03475); GUN2 (Heme oxygenase 1, At2g26670); GUN3 (Phytochromobilin synthase, At3g09150); GUN4 (Regulator of Mg-porphyrin synthesis, At3g59400); GUN5 (Mg-chelatase subunit H, At5g13630); CHLI (Mg-chelatase subunit I, At4g18480 and At5g45930); CHLD (Mg-chelatase subunit D, At1g08520); CHLM (MgProtoporphyrin IX methyltransferase, At4g25080); CRD1 (MgProtoporphyrin IX monomethylester cyclase, At3956940); FC1 (Ferrochelatase 1, At5g26030); FC2 (Ferrochelatase 2, At2g30390).

\section{Additional file 2: Alignment of TSPO sequences from different} organisms. ClustalW sequence alignment of TSPO proteins from Rhodobacter sphaeroides (AF195122.1), Rattus norvegicus (J05122) and Arabidopsis TSPO (AtTSPO - At2g47770). The numbers in the left side represent the amino acid position from the primary protein. In the consensus line the conserved aminoacids are highlighted as $(*)$, and as (.) when one conserve position is observed. M1, M21 and M42 AtTSPO isoforms are highlighted. The black arrow represents the first 80 aminoacids (AtTSPO80aa) of Arabidopsis TSPO.

Additional file 3: AtM42TSPO:eGFP co-localizes with mitotracker in Arabidopsis thaliana. AtM42TSPO:eGFP 5-day-old seedlings transgenic lines $(A-C)$ were incubated with mitotracker to identify mitochondria. (A) Image from GFP channel is shown in green. (B) Image from mitotracker channel is shown in red. (C) Merge between GFP and mitotracker channels shown in yellow. Scale bar $=50 \mu \mathrm{M}$.

Additional file 4: Immunoblot showing that AtTSPO:eGFP accumulates during salt stress. Immunoblot analysis of protein level in all three isoforms of OxAtTSPO:eGFP (OxM1TSPO:eGFP, OxM21TSPO:eGFP and OXM42TSPO:eGFP) during salt stress show accumulation of the protein. As a control wild-type plants and plants over-expressing GFP (OxeGFP) were used. Anti-UGPase and Red-ponceau staining were used as loading controls. Equal amounts of total protein were loaded.

Additional file 5: Immunoblot of chloroplasts prepared from OxTSPO:eGFP plants. Arabidopsis chloroplasts were prepared from 10days-old seedlings either untreated or treated with $150 \mathrm{mM} \mathrm{NaCl}$ and immunoblotted with antibodies to GFP, RuBisCo, D1 and UGPase. Equal amounts of OXM1TSPO:eGFP chloroplast protein samples were loaded in each lane. (TP) Total Protein; (Chl) Chloroplast protein; PP (Protease Protection treatment).

\section{Abbreviations}

ABA: Abscisic acid; ALA: 5-Aminolevulinate; CFP: Cyan fluorescent protein; D1: photosystem II reaction center D1 protein; HMR: Hemera protein; GFP: Green fluorescent protein; GUS: $\beta$-Glucuronidase; Mg-Proto IX: MgProtoporphyrin IX; MV: Methyl viologen; ROS: Reactive oxygen species; RUBISCO: Ribulose-1,5-biphosphate carboxylase; TSPO: 18 kDa Translocator protein; UGPase: UDP-glucose pyrophosphorylase; VAMP: Vesicle associated membrane protein; YFP: Yellow fluorescent protein.

\section{Acknowledgements}

We thank Jesse Woodson, Juan M. Perez-Ruiz, Ana Lucia Giannini, Amanda Mangeon and Marcio Castro Silva-Filho for providing critical feedback on the manuscript. The Salk Institute provided the insertion mutant lines and ABRC for providing material. Pedro Paulo de Abreu Manso and Bernardo Miguel de Oliveira Pascarelli from the Rede de Plataformas Tecnológicas da Fundação Instituto Oswaldo Cruz (FioCruz) for technical support on the confocal microscopy analysis. Luiza da Silva for technical support with plant transformation. EBP was supported by PhD fellowship from CAPES

(Coordenação de Aperfeiçoamento de Pessoal de Nível Superior) and SWE fellowship from CNPq (Conselho Nacional de Desenvolvimento Científico e Tecnológico), The Salk Institute and Balcoffee Trading Intermediações Ltda. YJ is supported by a long-term fellowship from the European Molecular Biology Organization (EMBO) and from the Marc and Eva Stern Foundation. BJSCO is supported by fellowship F32GM086037 from the National Institutes of Health and National Institute of General Medical Sciences. JGU is supported by American Cancer Society grant RSG-05-196-01-CCG. This work was supported by grants from DOE FG02-04ER15540 from the U.S. Department of Energy to JC and the Conselho Nacional de Desenvolvimento Científico e Tecnológico (CNPq) and the Fundação Carlos Chagas Filho de Amparo à Pesquisa do Estado do Rio de Janeiro (FAPERJ) to GSM.

\section{Author details}

'Laboratório de Genômica Funcional e Transdução de Sinal, Departamento de Genética, Universidade Federal do Rio de Janeiro, Rio de Janeiro, Brazil. 2Plant Biology Laboratory, The Salk Institute, 10010 North Torrey Pines Road, La Jolla, CA 92037, USA. ${ }^{3}$ Howard Hughes Medical Institute 4000 Jones Bridge RoadChevy Chase, MD 20815-6789, USA. ${ }^{4}$ Laboratório de Biomineralização, Instituto de Ciências Biomédicas, Universidade Federal do Rio de Janeiro, Brasil.

\section{Authors' contributions}

EBP, JC and GSM conceived and designed the experiments. EBP performed all the experiments, analyzed the data and wrote the paper. YJ helped in the confocal microscopy analyses. BJSCO helped in the fractionation experiment. LRA and JGU gave technical support. JC and GSM were project supervisors, participated in the discussion of all experiments from the project and preparation of the manuscript. All authors read and approved the final manuscript.

Received: 14 January 2011 Accepted: 20 June 2011

Published: 20 June 2011

\section{References}

1. Beale SI: Enzymes of chlorophyll biosynthesis. Photosynth Res 1999, 60:43-73. 
2. Papenbrock J, Grimm B: Regulatory network of tetrapyrrole biosynthesis studies of intracellular signaling involved in metabolic and developmental control of plastids. Planta 2001, 213:667-681.

3. Vavilin DV, Vermaas WFJ: Regulation of the tetrapyrrole biosynthetic pathway leading to heme and chlorophyll in plants and cyanobacteria. Physiol Plant 2002, 115:9-24.

4. Reinbothe $S$, Reinbothe $C$ : The regulation of enzymes involved in chlorophyll biosynthesis. Eur J Biochem 1996, 237:323-343.

5. Grimm B: Novel insights in the control of tetrapyrrole metabolism of higher plants. Curr Opin Plant Biol 1998, 1:245-250

6. Papadopoulos V, Boujrad N, Ikonomovic MD, Ferrara P, Vidic B: Topography of the Leydig cell mitochondrial peripheral-type benzodiazepine receptor. Mol Cell Endocrinol 1994, 104:R5-R9.

7. McEnery MW, Snowman AM, Trifiletti RR, Snyder SH: Isolation of the mitochondrial benzodiazepine receptor: association with the voltagedependent anion channel and the adenine nucleotide carrier. Proc Natl Acad Sci USA 1992, 89:3170-3174.

8. Papadopoulos V, Baraldi M, Guilarte TR: Translocator protein ( $18 \mathrm{kDa})$ : new nomenclature for the peripheral-type benzodiazepine receptor based on its structure and molecular function. Trends Pharmacol Sci 2006, 27:402-409.

9. Li H, Papadopoulos V: Peripheral-type benzodiazepine receptor function in cholesterol transport. Identification of a putative cholesterol recognition/interaction amino acid sequence and consensus pattern. Endocrinology 1998, 139:4991-4997.

10. Papadopoulos V: Structure and function of the peripheraltype benzodiazepine receptor in steroidogenic cells. Proc Soc Exp Biol Med 1998, 217:130-142.

11. Lacapere JJ, Papadopoulos V: Peripheral-type benzodiazepine receptor: structure and function of a cholesterol-binding protein in steroid and bile acid biosynthesis. Steroids 2003, 68:569-585.

12. O'Hara MF, Craig RC, Nemeth KR, Charlap JH, Knudsen TB: Mitochondrial benzodiazepine receptors regulate oxygen homeostasis in the early mouse embryo. Reprod Toxicol 2003, 17:365-75.

13. Galiegue S, Casellas P, Kramar A, Tinel N, Simony-Lafontaine J: Immunohistochemical assessment of the peripheral benzodiazepine receptor in breast cancer and its relationship with survival. Clin Cancer Res 2004, 10:2058-2064.

14. Taketani S, Kohno H, Okuda M, Furukawa T, Tokunaga R: Induction of peripheral-type benzodiazepine receptors during differentiation of mouse erythroleukemia cells. A possible involvement of these receptors in heme biosynthesis. J Biol Chem 1994, 269:7527-7531.

15. Yeliseev AA, Kaplan S: A sensory transducer homologous to the mammalian peripheral-type benzodiazepine receptor regulates photosynthetic membrane complex formation in Rhodobacter sphaeroides 2.4.1. J Biol Chem 1995, 270:21167-75.

16. Yeliseev AA, Kaplan S: A novel mechanism for the regulation of photosynthesis gene expression by the TspO outer membrane protein of Rhodobacter sphaeroides 2.4.1. J Biol Chem 1999, 274:21234-43.

17. Yeliseev AA, Krueger KE, Kaplan S: A mammalian mitochondrial drug receptor functions as a bacterial "oxygen" sensor. Proc Natl Acad Sci USA 1997, 94:5101-6.

18. Lindemann P, Koch A, Degenhardt B, Hause G, Grimm B, Papadopoulos V: A novel Arabidopsis thaliana protein is a functional peripheral-type benzodiazepine receptor. Plant Cell Physiol 2004, 45:723-733.

19. Vanhee C, Guillon S, Masquelier D, Degand H, Deleu M, Morsomme P, Batoko H: A TSPO-related protein localizes to the early secretory pathway in Arabidopsis, but is targeted to mitochondria when expressed in yeast. Journal of Experimental Botany 2010, 16:1-12.

20. Corsi L, Avallone R, Geminiani E, Cosenza F, Venturini I, Baraldia M: Peripheral benzodiazepine receptors in potatoes (Solanum tuberosum). Biochemical and Biophysical Research Communications 2004, 313:62-66.

21. Frank W, Baar K-M, Qudeimat E, Woriedh M, Alawady A, Ratnadewi D, Gremillon L, Grimm B, Reski R: A mitochondrial protein homologous to the mammalian peripheral-type benzodiazepine receptor is essential for stress adaptation in plants. The Plant Journal 2007, 51:1004-1018.

22. Guillaumot D, Guillon S, Deplanque T, Vanhee C, Gumy C, Masquelier D, Morsomme P, Batoko H: The Arabidopsis TSPO-related protein is a stress and abscisic acid-regulated, endoplasmic reticulum-Golgi-localized membrane protein. The Plant Journal 2009, 60:242-256.
23. Kreps JA, Wu Y, Chang HS, Zhu T, Wang X, Harper JF: Transcriptome changes for Arabidopsis in response to salt, osmotic, and cold stress. Plant Physiol 2002, 130:2129-41.

24. Alonso JM, Stepanova AN, Leisse TJ, Kim CJ, Chen H, Shinn P, Stevenson DK, Zimmerman J, Barajas P, Cheuk R, Gadrinab C, Heller C, Jeske A, Koesema E, Meyers CC, Parker H, Prednis L, Ansari Y, Choy N, Deen H, Geralt M, Hazari N, Hom E, Karnes M, Mulholland C, Ndubaku R, Schmidt I, Guzman P, Aguilar-Henonin L, Schmid M, et al: Genome-wide insertional mutagenesis of Arabidopsis thaliana. Science 2003, 301:653-7.

25. Chai M-F, Wei P-C, Chen Q-J, Rui A, Cheng J, Yang S, Wang X-C: NADK3, a novel cytoplasmic source of NADPH, is required under conditions of oxidative stress and modulates abscisic acid responses in Arabidopsis. The Plant Journal 2006, 47:665-674.

26. Verma A, Nye JS, Snyder SH: Porphyrins are endogenous ligands for the mitochondrial (peripheral-type) benzodiazepine receptor. Proc Natl Acad Sci USA 1987, 84:2256-2260.

27. Mochizuki N, Brusslan JA, Larkin R, Nagatani A, Chory J: Arabidopsis genomes uncoupled 5 (GUN5) mutant reveals the involvement of Mgchelatase $\mathrm{H}$ subunit in plastid-to-nucleus signal transduction. Proc Natl Acad Sci USA 2001, 98:2053-2058.

28. Stephenson PG, Terry MJ: Light signalling pathways regulating the Mgchelatase branchpoint of chlorophyll synthesis during de-etiolation in Arabidopsis thaliana. Photochem Photobiol Sci 2008, 10:1243-52.

29. Hill CM, Pearson SA, Smith AJ, Rogers LJ: Inhibition of chlorophyll synthesis in Hordeum vulgare by 3-amino-2,3-dihydrobenzoicacid (gabaculine). Biosci Rep 1985, 5:775-81.

30. Grimm B, Smith AJ, Kannangara CG, Smith M: Gabaculine-resistant galutamate1-semialdehyde amino transferase of Synechococcus. J Biol Chem 1991, 266:12496-501.

31. Mayfield SP, Taylor WC: Carotenoid-deficient maize seedlings fail to accumulate light-harvesting chlorophyll a/b binding protein (LHCP) mRNA. Eur J Biochem 1984, 144:79-84.

32. Oelmüller $\mathrm{R}$, Mohr $\mathrm{H}$ : Photooxidative destruction of chloroplast and its consequences for expression of nuclear genes. Planta 1986, 167:106-113.

33. Taylor WC: Regulatory interactions between nuclear and plastid genomes. Ann Rev Plant Physiol Plant Mol Biol 1989, 40:211-233.

34. Susek RE, Ausubel FM, Chory J: Signal transduction mutants of Arabidopsis uncouple nuclear $C A B$ and RBCS gene expression from chloroplast development. Cell 1993, 74:787-99.

35. Larkin RM, Alonso JM, Ecker JR, Chory J: GUN4, a regulator of chlorophyll synthesis and intracellular signaling. Science 2003, 299:902-6.

36. Chow KS, Singh DP, Walker AR, Smith AG: Two different genes encode ferrochelatase in Arabidopsis: mapping, expression and subcellular targeting of the precursor proteins. Plant $J$ 1998, 15:531-41.

37. Kumar AM, Söll D: Antisense HEMA1 RNA expression inhibits heme and chlorophyll biosynthesis in Arabidopsis. Plant Physiol 2000, 122:49-56.

38. Ishikawa A, Okamoto $H$, Iwasaki $Y$, Asahi T: A deficiency of coproporphyrinogen III oxidase causes lesion formation in Arabidopsis. Plant J 2001, 27:89-99.

39. Tottey S, Block MA, Allen M, Westergren T, Albrieux C, Scheller HV, Merchant S, Jensen PE: Arabidopsis CHL27, located in both envelope and thylakoid membranes, is required for the synthesis of protochlorophyllide. Proc Natl Acad Sci USA 2003, 100:16119-24.

40. Peter E, Rothbart M, Oelze M-L, Shalygo N, Dietz K-J, Grimm B: Mgprotoporphyrin monomethylester cyclase deficiency and effects on the tetrapyrrole metabolism in different light conditions. Plant and Cell Phys 2010, 51:1229-41.

41. Christensen AH, Quail PH: Ubiquitin promoter-based vectors for highlevel expression of selectable and/or screenable marker genes in monocotyledonous plants. Transgenic Res 1996, 5:213-8.

42. Chen M, Galvão RM, Li M, Burger B, Buger J, Bolado J, Chory J: Arabidopsis HEMERA/PTAC12 initiates photomorphogenesis by phytochromes. Cell 2010, 141:1230-1240.

43. Obara K, Sumi K, Fukuda H: The Use of Multiple Transcription Starts Causes the Dual Targeting of Arabidopsis Putative Monodehydroascorbate Reductase to Both Mitochondria and Chloroplasts. Plant Cell Physiol 2002, 43(7):697-705.

44. von Braun SS, Sabetti A, Hanic-Joyce PJ, Gu J, Schleiff E, Joyce PBM: Dual targeting of the tRNA nucleotidyltransferase in plants: not just the signal. Journal of Experimental Botany 2007, 58(5/16):4083-4093. 
45. Hardwick M, Fertikh D, Culty M, Li H, Vidic B, Papadopoulos V: Peripheraltype benzodiazepine receptor (PBR) in human breast cancer: Correlation of breast cancer cell aggressive phenotype with PBR expression, nuclear localization and PBR-mediated cell proliferation and nuclear transport of cholesterol. Cancer Research 1999, 59:831-842.

46. Krause K, Krupinska K: Nuclear regulators with a second home in organelles. Trends in Plant Science 2009, 14:194-199.

47. Soltys BJ, Gupta RS: Mitochondrial-matrix proteins at unexpected locations: are they exported? Trends Biochem Sci 1999, 24:174-177.

48. Isenmann S, Khew-Goodall Y, Gamble J, Vadas M, Wattenberg BW: A spliceisoform of vesicle-associated membrane protein-1 (VAMP-1) contains a mitochondrial targeting signal. Mol Biol Cell 1998, 9:1649-1660.

49. Andersson MX, Goksör M, Sandelius AS: Optical manipulation reveals strong attracting forces at membrane contact sites between endoplasmic reticulum and chloroplasts. J Biol Chem 2007, 282:1170-1174.

50. Segui-Simarro JM, Coronado MJ, Staehelin LA: The mitochondrial cycle of Arabidopsis shoot apical meristem and leaf primordium meristematic cells is defined by a perinuclear tentaculate/cage-like mitochondrion. Plant Physiol 2008, 148:1380-1393.

51. Watanabe $K$, Tanaka T, Hotta $Y$, Kuramochi H, Takeuchi Y: Improving salt tolerance of cotton seedlings with 5 -aminolevulinic acid. Plant Growth Regul 2000, 32:99-103.

52. Nishihara H, Kizaka-Kondoh S, Insel PA, Eckmann L: Inhibition of apoptosis in normal and transformed intestinal epithelial cells by CAMP through induction of inhibitor of apoptosis protein (IAP)-2. Proc Natl Acad SCi USA 2003, 22:8921-6.

53. Watanabe K, Ryoji O, Rasid MM, Suliman A, Tohru T, Hitoshi K, Yasutomo T: Effects of 5-aminolevulinic acid to recover salt damage on cotton, tomato, and wheat seedlings in Saudi Arabia. J Arid Land Stud 2004, 14:105-113.

54. Wang $L$, Jiang WB, Liu H, Liu WQ, Kang L, Hou XL: Promotion of 5aminolevulinic acid on germination of pakchoi (Brassica campestris ssp. chinensis var. communis Tsen et Lee) seeds under salt stress. J Integr Plant Biol 2005, 9:1084-91.

55. Watanabe K, Ryoji O, Rasid MM, Suliman A, Tohru T, Hitoshi K, Zhang ZJ, Li HZ, Zhou WJ, Takeuchi Y, Yoneyama K: Effect of 5-aminolevulinic acid on development and salt tolerance of potato (Solanum tuberosum L.) microtubers in vitro. Plant Growth Regul 2006, 49:27-34.

56. Youssef T, Awad MA: Mechanisms of enhancing photosynthetic gas exchange in date palm seedlings (Phoenix dactylifera L.) under salinity stress by a 5-aminolevulinic acid-based fertilizer. J Plant Growth Regul 2008, 27:1-9.

57. Jung S, Back K, Yang K, Kuk Yl, Chon SU: Defence response produced during photodynamic damage in transgenic rice overexpressing 5aminolevulinic acid synthase. Photosynthetica 2008, 46:3-9.

58. Zhang Z-P, Yao Q-H, Wang L-J: Expression of yeast Hem1 gene controlled by Arabidopsis HemA1 promoter improves salt tolerance in Arabidopsis plants. BMB reports 2010, 330-336.

59. Abdelkader AF, Aronsson $\mathrm{H}$, Sundqvist $\mathrm{C}$ : High salt stress in wheat leaves causes retardation of chlorophyll accumulation due to a limited rate of protochlorophyllide formation. Physiol Plant 2007, 130:157-166.

60. Strand A, Asami T, Alonso J, Ecker JR, Chory J: Chloroplast to nucleus communication triggered by accumulation of Mg-protoporphyrinIX. Nature 2003, 421:79-83

61. Murashige T, Skoog F: A revised medium for rapid growth and bioassays with tobacco tissue cultures. Physiol Plant 1962, 15:473-497.

62. Karime M, Inzé D, Depicker A: GATEWAY ${ }^{\mathrm{TM}}$ vectors for Agrobacteriummediated plant transformation. Trends in Plant Science 2002, 5:193-5.

63. Clough SJ, Bent AF: Floral dip: a simplified method for Agrobacteriummediated transformation of Arabidopsis thaliana. Plant J 1998, 16:735-743.

64. Lichtenthaler HK: Chlorophyll and carotenoids: pigments of photosynthetic biomembranes. Methods Enzymol 1987, 148:349-382.

65. Fitzpatrick LM, Keegstra K: A method for isolating a high yield of Arabidopsis chloroplasts capable of efficient import of precursor proteins. Plant J 2001, 27:59-65.

66. Bradford MM: A rapid and sensitive method for the quantitation of microgram quantities of protein utilizing the principle of protein-dye binding. Analyt Biochem 1976, 72:248-254. doi:10.1186/1471-2229-11-108

Cite this article as: Balsemão-Pires et al:: The Arabidopsis translocator protein (AtTSPO) is regulated at multiple levels in response to salt stress and perturbations in tetrapyrrole metabolism. BMC Plant Biology 2011 11:108.

\section{Submit your next manuscript to BioMed Central and take full advantage of:}

- Convenient online submission

- Thorough peer review

- No space constraints or color figure charges

- Immediate publication on acceptance

- Inclusion in PubMed, CAS, Scopus and Google Scholar

- Research which is freely available for redistribution

Submit your manuscript at www.biomedcentral.com/submit
Biomed Central 